九州大学学術情報リポジトリ

Kyushu University Institutional Repository

Clinical outcomes of allogeneic stem cell transplantation for relapsed or refractory follicular lymphoma: a retrospective analys is by the Fukuoka Blood and Marrow Transplantation Group

伊藤，能清

https://doi.org/10.15017/1441339

出版情報：九州大学，2013，博士（医学），論文博士 バージョン:

権利関係：やむを得ない事由により本文ファイル非公開（2） 


\section{Clinical outcomes of allogeneic stem cell transplantation for relapsed or refractory follicular lymphoma: a retrospective analysis by the Fukuoka Blood and Marrow Transplantation Group}

Yoshikiyo Ito ${ }^{1}$, Toshihiro Miyamoto ${ }^{2}$, Tomohiko Kamimura ${ }^{1}$, Ken Takase ${ }^{3,5}$, Hideho Henzan ${ }^{3}$, Yasuo Sugio ${ }^{4}$, Koji Kato ${ }^{2}$, Yuju Ohno ${ }^{4}$, Tetsuya Eto ${ }^{3}$, Takanori Teshima ${ }^{6}$, Koichi Akashi ${ }^{2}$

1. Department of Hematology, Harasanshin Hospital, Fukuoka, Japan

2. Department of Medicine and Biosystemic Science, Graduate School of Medical Science, Kyushu University, Fukuoka, Japan

3. Department of Hematology, Hamanomachi Hospital, Fukuoka, Japan

4. Department of Internal Medicine, Kitakyushu Municipal Medical Center, Kitakyushu, Japan

5. Department of Hematology, National Kyushu Medical Center, Fukuoka, Japan

6. Department of Hematology and Oncology, Hokkaido University Graduate School of Medicine, Sapporo, Japan

Running title; Allo-SCT for follicular lymphoma

Key Words; allogeneic stem cell transplantation, follicular lymphoma,

Correspondence should be addressed to:

Toshihiro Miyamoto, MD, PhD

Medicine and Biosystemic Science,

Kyushu University Graduate School of Medical Sciences

3-1-1 Maidashi, Higashi-ku, Fukuoka 812-8582, Japan,

Phone: 81-92-642-5230 Fax: 81-92-642-5247

E-mail: toshmiya@intmed1.med.kyushu-u.ac.jp 


\begin{abstract}
Allogeneic hematopoietic stem cell transplantation (allo-SCT) is considered as the only curative treatment for relapsed or refractory follicular lymphoma (FL), but it has a high treatment-related mortality rate. Only a few reports, however, have described the efficacy of allo-SCT for FL in the Japanese population. We have retrospectively analyzed the outcome of allo-SCT in 30 patients with FL. Seventeen (56.7\%) patients were chemorefractory, whereas $13(43.3 \%)$ were chemosensitive. An estimated 2-year overall survival rate (OS) and relapse rate of all patients $46.7 \%$ and $20.0 \%$, respectively. There were no significant differences in the estimated 2-year OS rate between patients who received myeloablative conditioning and those who received reduced-intensity conditioning $(\mathrm{P}=0.98)$, and among the recipients of related bone marrow $(\mathrm{BM}) /$ peripheral blood stem cell, unrelated $\mathrm{BM}$ and umbilical cord blood $(\mathrm{P}=0.20)$. In patients who were either chemosensitive or chemorefractory at allo-SCT, the 2-year OS rate was $69.2 \%$ and $29.4 \%(\mathrm{P}=0.06)$. Patients with mild-to moderate acute GVHD had better the 2-year PFS rate compared with patients who had severe acute GVHD ( $\mathrm{P}=0.01)$, but not better PFS compared with patients who had no acute GVHD (P=0.12). Our results suggest that the graft-versus-lymphoma effects of allo-SCT may provide survival benefits even in patients with chemorefractory FL.
\end{abstract}




\section{Introduction}

Although follicular lymphoma (FL) responds well to first-line therapy, relapses requiring therapeutic interventions are common, with disease-free intervals becoming progressively shorter $[1,2]$. Allogeneic hematopoietic stem cell transplantation (allo-SCT) can result in long-term control of FL, in part, through the graft-versus-lymphoma (GVL) immune response [3,4]. A comparative retrospective study revealed a significantly lower relapse rate in patients with relapsed FL who underwent allo-SCT compared with those who underwent autologous SCT (auto-SCT) or salvage chemotherapy [5,6]. Therefore, allo-SCT has become the treatment of choice for patients with relapsed or refractory FL [7,8]. However, the potential survival benefits of allo-SCT compared with that of auto-SCT is often offset by the high treatment-related mortality (TRM) rate, due to direct toxicity and high incidence of severe graft-versus-host disease (GVHD). Recently, the use of reduced-intensity conditioning (RIC) regimen has become standard practice in older patients or those with comorbid physical conditions to decrease the TRM rate of allo-SCT. In addition, umbilical cord blood (UCB) is increasingly preferred for patients who do not have access to a human leukocyte antigen (HLA)-matched donor because of the availability of stored transplantable units and the lower risk of GVHD, thus permitting less stringent HLA matching. Because of these advances, allo-SCT is rapidly being adopted for patients with FL requiring allo-SCT. However, only few reports have described the efficacy of allo-SCT for FL in the Japanese population [8-10].

In this study, we retrospectively analyzed the clinical outcomes of 30 Japanese patients with FL who underwent allo-SCT between 1997 and 2010 using different graft sources including bone marrow (BM), peripheral blood stem cell (PBSC), and UCB. This is the era after the introduction of rituximab, but prior to the availability of the alkylating agent, bendamustine [11]. Radioimmunoconjugated drug ${ }^{90}$ Y-ibritumomab tiuxetan [12] was available since 2008 in Japan, but no patients had been treated by ${ }^{90}$ Y-ibritumomab tiuxetan prior to allo-SCT in our study. On the basis of our observations and previously reported literatures, we have 
discussed the implications of our findings on the role of allo-SCT in the new drug era for FL treatment.

\section{Patients and methods}

\section{Patient Characteristics}

Between 1997 and 2010, 30 patients (males, 15; females, 15; median age, 52 years; range, 32-65 years) with relapsed or refractory FL who underwent allo-SCT at four of the Fukuoka Blood and Marrow Transplantation Group institutions were enrolled in this study (Table 1). The World Health Organization (WHO) criteria were used for the diagnosis of FL [13]. The median duration from diagnosis to transplantation was 38.5 months (range, 4-122), the median follow-up duration was 21.4 months in all of the patients (range, 0.4-165.4), and the median follow-up duration of surviving patients was 57.1 months (range 27.8-165.4). All patients underwent chemotherapy in combination with rituximab prior to allo-SCT; the median number of previous chemotherapy regimen was four (range, 2-8), and two patients had received high-dose chemotherapy and autologous peripheral blood stem cell transplantation (PBSCT). Only five patients underwent re-biopsy before allo-SCT. All of the five patients demonstrated progression of degree of FL grade and one of the patients progressed to diffuse large B-cell lymphoma. In our study, re-biopsy rate was low (17\%); therefore, there was a possibility to include patients with histologic transformation to more aggressive lymphoma. Response criteria were based on guidelines from the international workshop on non-Hodgkin's lymphoma [14]. At the time of allo-SCT, four patients were in complete remission (CR), nine in partial remission $(\mathrm{PR})$, and 17 in progressive disease $(\mathrm{PD})$.

Conditioning Regimen and Graft-versus-Host Disease Prophylaxis

The conditioning regimens included myeloablative conditioning (MAC) in 13 patients and RIC in 17 patients. MAC regimens included intravenous busulfan and cyclophosphamide $(\mathrm{Bu}$ and $\mathrm{CY} ; 12.8 \mathrm{mg} / \mathrm{kg}$ and 
$120 \mathrm{mg} / \mathrm{kg}$, respectively) in 2 patients; Bu and melphalan (Bu and L-PAM; $16 \mathrm{mg} / \mathrm{kg}$ oral and $200 \mathrm{mg} / \mathrm{m}^{2}$ intravenous, respectively) in 1 patient; total body irradiation (TBI) plus intravenous CY (TBI and CY; 12Gy and $120 \mathrm{mg} / \mathrm{kg}$, respectively) or TBI/CY plus either intravenous etoposide or thiotepa in 10 patients. RIC, with or without low-dose TBI (2-4 Gy), included intravenous fludarabine and $\mathrm{Bu}$ in 10 patients [Flu/Bu; either $125-180 \mathrm{mg} / \mathrm{m}^{2}$ plus Bu $16 \mathrm{mg} / \mathrm{kg}$ oral or $6.4 \mathrm{mg} / \mathrm{kg}$ intravenous with or without low-dose TBI (2-4 Gy), respectively]; intravenous Flu/L-PAM, in 5 patients $\left[125-180 \mathrm{mg} / \mathrm{m}^{2}\right.$ and $140 \mathrm{mg} / \mathrm{m}^{2}$ intravenous with or without low-dose TBI (2-4 Gy), respectively], and 2 received other regimens such as rituximab, cladribine and L-PAM (Table 1). In the MAC group, median age at allo-SCT was 50 years (range, 32-56) with 7 patients aged $>50$ years. In the RIC group, median age at allo-SCT was 53 years (range, 47-65) with 13 patients aged $>50$ years; patients in the RIC group were significantly older than those in the MAC group $(\mathrm{P}<0.01)$. None of the patients in the MAC group had undergone an auto-SCT prior to allo-SCT compared with two patients in the RIC group. At the time of allo-SCT, four patients in the MAC group, and nine patients in the RIC group were chemosensitive $(\mathrm{CR}+\mathrm{PR})($ Table 1$)$; this difference was not statistically significant $(\mathrm{P}=0.11)$.

Related bone marrow transplantation (BMT) was performed in three patients, related PBSCT in 10, unrelated BMT in 12, and unrelated umbilical cord blood transplantation (UCBT) in five (Table 1). GVHD prophylaxis included cyclosporine $(n=15)$ and tacrolimus $(n=15)$ combined with methotrexate or mycophenolate mofetil as described previously $[15,16]$. None of the patients received anti-thymocyte globulin during the conditioning regimen.

Assessment of Engraftment, GVHD and Survival

Engraftment was defined as an absolute neutrophil count of more than $0.5 \times 10^{9} / \mathrm{L}$ for three consecutive days. Acute and chronic GVHD were diagnosed and graded according to the standard criteria described previously [17-19]. Overall survival (OS) rate was computed from the date of transplantation. 


\section{Statistical Analysis}

The probability of survival was estimated using the Kaplan-Meier method [20]. The effects on survival in patient and disease variables were examined using the log-rank test. In addition, because the risk of chronic GVHD (cGVHD) usually begins by day 50 following allo-SCT, we performed a "landmark" analysis, 50 days after allo-SCT, of OS rate relative to the GVHD grade [21].

\section{Results}

Engraftment

Twenty-six patients achieved engraftment, and the median time for neutrophil count recovery was 16 days (range 10-29 days) following allo-SCT. Engraftment was not analyzed in 3 patients (1 BM, 1 PBSC, and 1 UCB recipient) because of fatal disease progression $(n=1)$, sinusoidal obstruction syndrome (SOS; $n=$ 1), or thrombotic microangiopathy (TMA; $n=1$ ). Primary engraftment failure occurred in one UCB recipient.

\section{Graft-versus-Host Disease}

Of the 26 evaluable patients, 17 (65.4\%) developed acute GVHD (aGVHD), including nine patients (34.6\%) with grade I disease, four patients (15.4\%) with grade II disease, and four patients (15.4\%) with grade III-IV disease (Table 2). Fifteen (60.0\%) of the 25 patients who survived longer than 50 days developed cGVHD, which was limited in four and extensive in 11 (Table 2). None of the patients received a donor lymphocyte infusion.

\section{Survival}

With the median follow-up of 21.4 months, the Kaplan-Meier estimate of total OS and 
progression free survival (PFS) rates at 2 years were $46.7 \%$ and $46.7 \%$, respectively, with 15 patients being disease-free (Figure 1a). There was no significant difference in the estimated 2-year OS rate in patients who underwent MAC $(46.2 \%, n=13)$ and RIC $(47.1 \%, n=17)(P=0.98$; Figure $1 b)$. In the related BM/PBSC ( $n$ = 13), unrelated BM $(n=12)$, and UCB $(n=5)$, the estimated 2-year OS rate were $38.5 \%, 66.7 \%$, and $20.0 \%$, respectively (UCB vs. unrelated BM; $\mathrm{P}=0.20$; Figure 1c). In patients who were either chemotherapy-sensitive (CR + PR) or chemorefractory at allo-SCT, the estimated 2-year OS was $69.2 \%$ and 29.4\%, respectively $(\mathrm{P}=0.06$; Figure $1 \mathrm{~d})$.

\section{Effects of Graft-versus-Host Disease on Survival and Mortality}

Further, we compared survival rates relative to the severity of aGVHD in 26 patients. Two-year PFS was estimated to be $44.4 \%, 76.9 \%$, and $0 \%$ in patients with grade 0 , I-II, or grade III-IV aGVHD, respectively (Figure 2a). PFS at 2 years was shorter in the patients with grade III-IV than those with either grades 0 or I-II $(\mathrm{P}=0.03$ and $\mathrm{P}<0.01$, respectively). There was no significant difference in the 2-year PFS rate between the patients with grade 0 and $\mathrm{I}-\mathrm{II}$ aGVHD $(\mathrm{P}=0.12)$. The cause of death according to the grade of aGVHD is summarized in Table 2. The main cause of death among patients without aGVHD $(n=9)$ and those with grade III-IV $(n=4)$ were cGVHD $(n=2 ; 22.2 \%)$ and aGVHD $(n=3 ; 75.0 \%)$, respectively. In patients with grade I-II aGVHD $(\mathrm{n}=13)$, specific cause of death was not observed.

In the 25 patients who survived for longer than 50 days after allo-SCT, there were no significant differences in the estimated 2-year PFS rate among the patients who developed or did not develop cGVHD (None ; 40.0\%, Limited ; 75.0\%, Extensive ; 63.6\%; $\mathrm{P}=0.44$ ) (Figure 2b). The cause of death according to the grade of cGVHD is summarized in Table 2. The main cause of death among patients without cGVHD $(n=$ $10)$ and those with extensive cGVHD $(n=11)$ were relapse $(n=3 ; 30.0 \%)$ and cGVHD $(n=3 ; 27.3 \%)$, respectively. In patients with limited cGVHD $(n=4)$, specific cause of death was not observed. In patients 
who developed cGVHD, relapse was not observed.

Relapse, TRM and Causes of Death

Four patients (13.3\%) exhibited disease progression after allo-SCT (median 90 days; range,

11-593 days) and died because of the underlying disease. The treatment-related mortality rates and relapse rate at 2 year were $33.3 \%$ and $20.0 \%$, respectively. Of 17 patients who suffered from treatment-related deaths, 6 patients died of GVHD: acute GVHD in 3 patients, chronic GVHD in 3 patients. The other cause of death was SOS/TMA in 2, multiple organ failure in 1 , acute pancreatitis in 1 , interstitial pneumonitis in 1 , invasive pulmonary aspergillosis after second UCBT in 1, and sudden death in 1 .

\section{Discussion}

FL is a slow, progressive B-cell malignancy with a median survival time of $8-10$ years from diagnosis. Although the availability of rituximab has improved both the outcome and survival of FL [22,23], patients with relapsed or refractory FL are advised to undergo allo-HSCT before they receive excessive chemotherapies and their physical condition is exacerbated by the adverse effects. The previous reports of allo-SCT for relapsed and refractory FL are summarized in Table3 [8,24-32]. PFS and OS rates among the patients who received allo-SCT with RIC varied between approximately $40 \%$ and $80 \%$, which was almost equivalent to those of our result. Two large registry studies from the Center for International Blood and Marrow Transplant Research (CIBMTR) and the European Group for Blood and Marrow Transplantation (EBMT) on patients with relapsed FL revealed that myeloablative allo-SCT has a significantly lower rate of relapse than auto-SCT; however, both transplants have similar long-term OS rates (50-62\% at 4-5 years) because of a $30-38 \%$ increase in the TRM rate in patients who underwent allo-SCT $[32,33]$. On the basis of these results, allo-SCT with RIC regimen is recognized as one of the promising conditioning regimens due to 
its reduced non-relapse mortality (NRM) rate and effective GVL effect.

Several studies have shown that FL is highly sensitive to the GVL effect, making allo-SCT a promising treatment modality with curative potential for relapsed or chemotherapy-resistant FL [4,34]. Although the development of severe GVHD is associated with poor outcome, mild-to-moderate aGVHD may confer a lower risk of disease progression and be beneficial for survival after allo-SCT for acute myeloid leukemia, chronic myelogenous leukemia, and adult T-cell leukemia/lymphoma [35-37]. In our study, the 2-year PFS rate was superior in patients who developed mild-to-moderate aGVHD than in those who developed either no aGVHD or severe aGVHD and relapse was not observed in the patients with cGVHD. The impact of GVHD on clinical outcomes after allo-SCT or FL remains unknown. However, the previous study showed excessive GVHD prophylaxis such as T-cell depletion caused a higher relapse rate [38]. These results suggested that mild-to-moderate aGVHD and cGVHD may have a beneficial influence on survival via GVL effects. However, further large-scale studies are required to assess the impact of acute and chronic GVHD on survival of patients with FL.

The reduced risk of relapse following MAC conditioning with allo-SCT offset by NRM associated with an intensive preparative regimen. Therefore, the use of allo-SCT following RIC is gradually increasing for patients with relapsed or refractory FL who are coping with comorbid physical conditions caused by disease progression and repeated chemotherapy. Two large registry studies have compared the outcomes of patients with FL who underwent allo-SCT following either RIC or MAC. The CIBMTR study found no difference in the 3-year PFS rate (RIC, $55 \%$ vs. MAC, $67 \%, \mathrm{P}=0.07$ ) or the 3 -year OS rate (RIC, $62 \%$ vs. MAC, $71 \%, \mathrm{P}=0.15$ ) in 208 patients with $\mathrm{FL}$, even though their analysis was limited to recipients of matched-related donors [25]. The EBMT study had 131 patients with solely unrelated donor grafts. In contrast to the CIBMTR study, the EBMT study found that recipients of the RIC regimens had a lower NRM and experienced a significantly improved PFS and OS by multivariate analysis [26]. However, in both the 
CIBMTR and EBMT studies, chemoresistance and a lower performance status were found to affect TRM, OS, and PFS rates adversely. In our report, we also found no significant difference while comparing the 2-year OS rates between patients in the RIC and MAC groups ( $47.1 \%$ vs. $46.2 \%$, respectively; $\mathrm{P}=0.98)$. In contrast, the 2-year OS rate was superior in chemosensitive patients $(\mathrm{CR}+\mathrm{PR})$ compared with those in the chemorefractory group (69.2\% vs. $29.4 \%$, respectively; $\mathrm{P}=0.06)$. The Grupo Español de Linfomasl/Tranplante de Médula Osea group reported significant differences in the 4-year DFS rate for 37 patients with FL who were treated by reduced-intensity stem cell transplantation (RIST) conditioning with progressive disease (PD), PR, or CR at allo-SCT $(29 \%, 48 \%$, and $64 \%$, respectively; $\mathrm{P}=0.02)$, whereas the 4-year cumulative incidence of NRM was $71 \%, 33 \%$, and $26 \%$, respectively $(\mathrm{P}=0.04)$ [29]. In addition, the French Society of Bone Marrow Graft Transplantation and Cellular Therapy group reported that the 3-year DFS rate in 73 patients with FL who were treated by RIST conditioning with $\mathrm{PD}, \mathrm{PR}$ or $\mathrm{CR}$ at allo-SCT was $32 \%, 52 \%$, and $66 \%$, respectively $(\mathrm{P}=$ $0.003)$, whereas the 3 -year cumulative incidence of NRM was $63 \%, 28 \%$, and $32 \%$, respectively $(\mathrm{P}=0.005)$ [39]. These data show that chemosensitivity at the time of allo-SCT, and not the conditioning intensity, is more reliable predictor of FL outcome in recipients of allo-SCT, and suggested that allo-SCT using RIC for relapsed FL may result in long-term surviving for some but significant proportion of patients with chemoresistant disease.

Recent trails have focused on how to incorporate novel molecular targeted agents into the allo-SCT conditioning regimen with the intention increasing the anti-lymphoma activity and decreasing toxicity. The M.D. Anderson group reported the outcome of patients with relapsed FL receiving allo-SCT in combination with a high-dose of rituximab, Flu, and CY [24]. Radioimmunotherapies, such as ${ }^{90}$ Y-ibritumomab tiuxetan, confer cytoreduction via targeted delivery of radiation with isotopes-conjugated monoclonal antibodies. The M.D. Anderson group also reported the outcomes for 26 patients with relapsed FL who were treated with RIC and allo-SCT using ${ }^{90}$ Y-ibritumomab tiuxetan in combination with Flu and CY 
[24]. The 3-year PFS rate for chemorefractory or chemosensitive patients were $80 \%$ and $87 \%$, respectively, whereas the 1-year TRM rate was only $8 \%$. The M.D. Anderson group also reported the results of combining allo-SCT with bendamustine in 16 patients with lymphoma. After a median follow-up period of 6 months, the OS and PFS rates for 16 patients with mantle cell lymphoma, FL, chronic lymphocytic leukemia and diffuse large B-cell lymphoma were $87 \%$ and $78 \%$, respectively [40]. Based on these results, it is feasible to incorporate novel agents into the allo-SCT regimens because of the acceptable TRM rates and promising efficacy in patients with chemorefractory FL.

In conclusion, our results revealed that allo-SCT was the only treatment that could result in long-term survival even for chemorefractory group, since GVHD may confer a beneficial influence on survival. Although allo-SCT possesses a GVL effect, it is also associated with severe TRM rates. Treatment of FL is now being further refined by bendamustine as the chemotherapy backbone and by determining the role of rituximab maintenance and radioimmunotherapy consolidation. Incorporating these novel agents into salvage chemotherapy before allo-SCT and / or conditioning regimen may improve the outcome of allo-SCT. Further large-scale studies are required to assess the efficacy and safety of allo-SCT in the era of these novel agents for patients with chemorefractory FL. 


\section{Acknowledgments}

We thank the nursing staff who cared for the patients at the Fukuoka BMT group.

This work was supported, in part, by a Grant-in-Aid from the Ministry of Education, Culture, Sports, Science, and Technology in Japan (23390254 \& 24659462 to T.M.).

\section{Figure Legends}

Figure 1. Kaplan-Meier estimates of (a) OS and PFS rates in all FL patients $(\mathrm{n}=30)$; (b) OS rates according to intensity of conditioning regimen; (c) OS rates according to stem cell source; (d) OS rates according to chemosensitivity at transplantation.

Figure 2. Kaplan-Meier estimates of the PFS rates according to (a) the grade of acute GVHD (excluding four cases of early death); (b) the grade of chronic GVHD in 25 patients who survived longer than 50 days after transplantation. 
Figure 1.
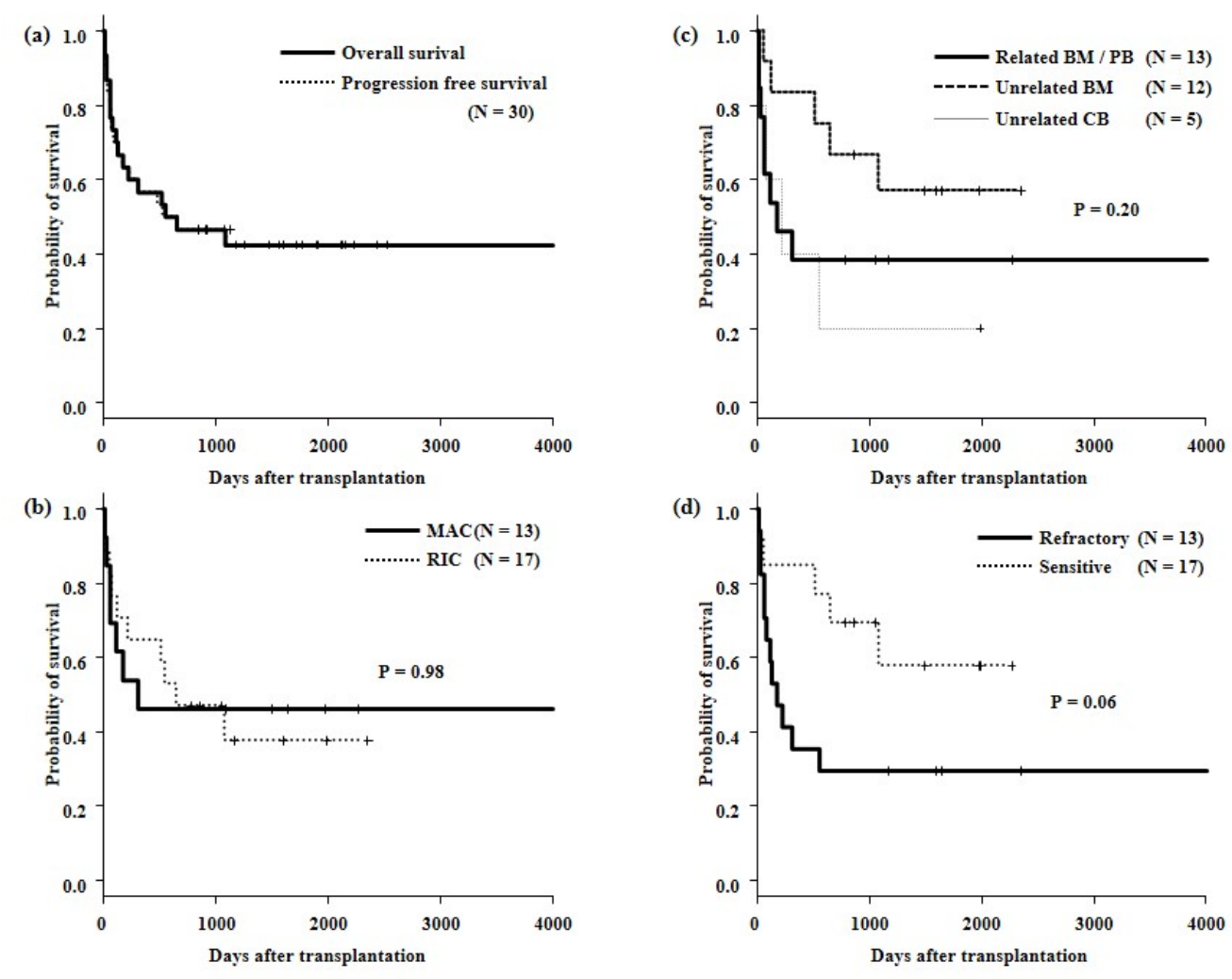
Figure 2.
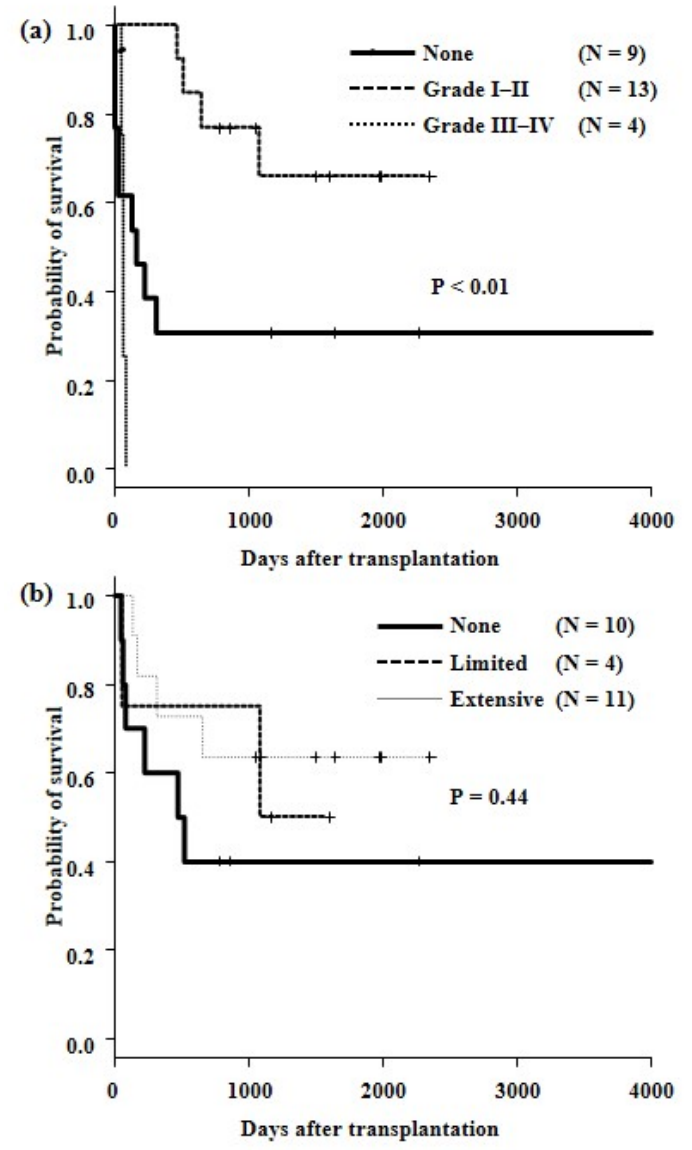
Table 1. Patient and Disease Characteristics

\begin{tabular}{|c|c|c|c|c|}
\hline Characteristics & $\begin{array}{c}\text { Total } \\
(\mathrm{N}=30)\end{array}$ & $\begin{array}{c}\text { MAC } \\
(\mathrm{N}=13)\end{array}$ & $\begin{array}{c}\text { RIC } \\
(\mathrm{N}=17)\end{array}$ & P value \\
\hline \multicolumn{5}{|l|}{ Sex } \\
\hline Male / Female & $15 / 15$ & $8 / 5$ & $7 / 10$ & 0.13 \\
\hline \multicolumn{5}{|l|}{ Age, years } \\
\hline Median (range) & $52(32-65)$ & $50(32-56)$ & $53(47-65)$ & $<0.01$ \\
\hline$<50$ & 11 & 6 & 4 & \\
\hline$\geq 50$ & 20 & 7 & 13 & \\
\hline \multicolumn{5}{|l|}{ Time from diagrosis to transplant, mouths } \\
\hline Median (range) & $38.5(4-122)$ & $26(4-122)$ & $42(8-120)$ & 0.06 \\
\hline \multicolumn{5}{|l|}{ Previous treatment } \\
\hline Previous chemotherapy lines & & & & 0.02 \\
\hline Median (range) & $4(2-8)$ & $2(2-5)$ & $4(2-8)$ & \\
\hline 2 & 9 & 8 & 1 & \\
\hline 3 & 5 & 2 & 3 & \\
\hline 4 & 6 & 1 & 5 & \\
\hline 5 & 7 & 2 & 5 & \\
\hline $6-8$ & 3 & 0 & 3 & \\
\hline Previous autograft & 2 & 0 & 2 & \\
\hline Stem cell source & & & & $<0.01$ \\
\hline Related BMT/PBSCT & 13 & 9 & 4 & \\
\hline Unrelated BMT & 12 & 4 & 8 & \\
\hline UCBT & 5 & 0 & 5 & \\
\hline \multicolumn{5}{|l|}{ Conditioning regimen } \\
\hline & \multirow{4}{*}{\multicolumn{2}{|c|}{$\begin{array}{l}\text { TBL } / C Y=\alpha ; 10 \\
\text { Bu/CY; } 2 \\
\text { BuL-PAM; } 1\end{array}$}} & \multirow{4}{*}{\multicolumn{2}{|c|}{$\begin{array}{l}\text { Flu/Bu = TBI; } 10 \\
\text { FluL-PAM = TBI; } 5 \\
\text { Rit/CdAL-PAM; } 1 \\
\text { TBI/thiotepa/CY; } 1\end{array}$}} \\
\hline & & & & \\
\hline & & & & \\
\hline & & & & \\
\hline Disease status at allo-SCT & & & & 0.11 \\
\hline Chemosensitive & 13 & 4 & 9 & \\
\hline $\mathrm{CR}$ & 4 & 1 & 3 & \\
\hline PR & 9 & 3 & 6 & \\
\hline Chemorefractory & 17 & 9 & 8 & \\
\hline
\end{tabular}

Abbreviations

MAC, myeloablative conditioning, RIC, Rechced-intensity conditioning, BMT, bone manow transplantation; PBSCT, peripheral blood stem cell transplantation; UCBT, umbilical cord blood transplamtation; TBI, total body irradiation; CY, cyclophosphamide; Bu, busulfan; L-PAM, melphalam; Flu, fludarabine; Rit, rituximab; CdA; cladribine; allo-SCT, allogeneic hematopoietic stem cell transplantation; CR, complete remission; $P R$, partial remission 
Table 2. Cause of death according to the grade of acute and chronic GVHD

\begin{tabular}{|c|c|c|c|c|}
\hline Acute GVHD ${ }^{* 1}$ & $\begin{array}{l}\text { None } \\
(\mathrm{n}=9)\end{array}$ & $\begin{array}{l}\text { I-II } \\
(n=13)\end{array}$ & $\begin{array}{l}\text { III-IV } \\
(\mathrm{n}=4)\end{array}$ & $\begin{array}{l}\text { Total } \\
(\mathrm{n}=26)\end{array}$ \\
\hline Dead (\%) & $5(55.5)$ & $4(30.8)$ & $4(100.0)$ & $13(50.0)$ \\
\hline \multicolumn{5}{|l|}{ Cause of death } \\
\hline Relapse (\%) & $1(11.1)$ & $1(7.7)$ & $1(25.0)$ & $3(11.5)$ \\
\hline aGVHD (\%) & $0(0.0)$ & $0(0.0)$ & $3(75.0)$ & $3(11.5)$ \\
\hline cGVHD (\%) & $2(22.2)$ & $1(7.7)$ & $0(0.0)$ & $3(11.5)$ \\
\hline Others (\%) & $2(22.2)$ & $2(15.4)$ & $0(0.0)$ & $4(15.4)$ \\
\hline Chronic GVHD ${ }^{2}$ & $\begin{array}{l}\text { None } \\
(n=10)\end{array}$ & $\begin{array}{l}\text { Limited } \\
(\mathrm{n}=4)\end{array}$ & $\begin{array}{l}\text { Extensive } \\
(\mathrm{n}=11)\end{array}$ & $\begin{array}{l}\text { Total } \\
(n=25)\end{array}$ \\
\hline Dead (\%) & $6(60.0)$ & $2(50.0)$ & $4(36.4)$ & $12(48.0)$ \\
\hline \multicolumn{5}{|l|}{ Cause of death } \\
\hline Relapse & $3(30.0)$ & $0(0.0)$ & $0(0.0)$ & $3(12.0)$ \\
\hline $\mathrm{aGVHD}$ & $2(20.0)$ & $1(25.0)$ & $0(0.0)$ & $3(12.0)$ \\
\hline cGVHD & $0(0.0)$ & $0(0.0)$ & $3(27.3)$ & $3(12.0)$ \\
\hline Others & $1(10.0)$ & $1(25.0)$ & $1(9.1)$ & $3(12.0)$ \\
\hline
\end{tabular}

Abbreviations

GVHD, graft-versus-host disease survival

${ }^{* 1}$ except four cases of graft failure

${ }^{* 2}$ patients who survived longer than 50 days after allo-SCT 


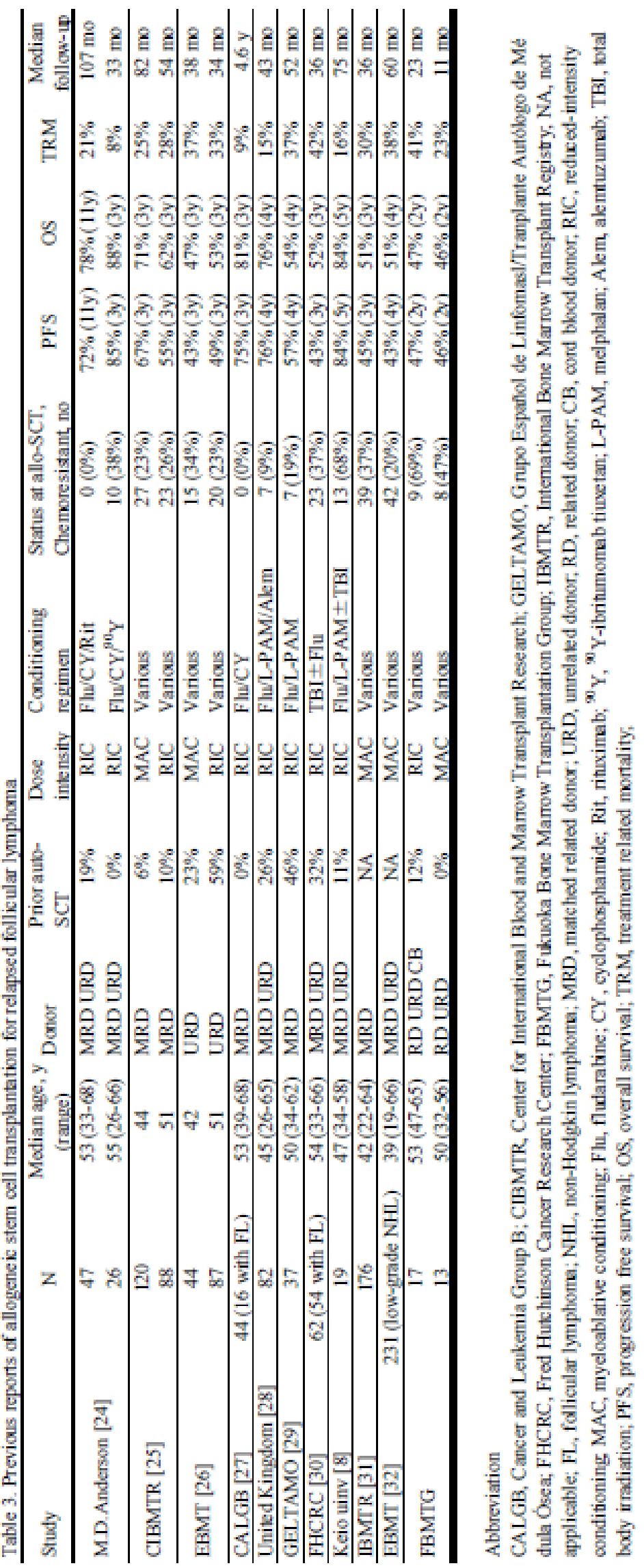


1. Gallagher CJ, Gregory WM, Jones AE, Stansfeld AG, Richards MA, Dhaliwal HS, et al. Follicular lymphoma: prognostic factors for response and survival. J Clin Oncol. 1986; 4:1470-80.

2. Johnson PW, Rohatiner AZ, Whelan JS, Price CG, Love S, Lim J, et al. Patterns of survival in patients with recurrent follicular lymphoma: a 20 -year study from a single center. J Clin Oncol. $1995 ; 13: 140-7$

3. Marks DI, Lush R, Cavenagh J, Milligan DW, Schey S, Parker A, et al. The toxicity and efficacy of donor lymphocyte infusions given after reduced-intensity conditioning allogeneic stem cell transplantation. Blood. 2002; 100:3108-14.

4. Mandigers CM, Verdonck LF, Meijerink JP, Dekker AW, Schattenberg AV, Raemaekers JM. Graft-versus-lymphoma effect of donor lymphocyte infusion in indolent lymphomas relapsed after allogeneic stem cell transplantation. Bone Marrow Transplant. 2003; 32:1159-63.

5. Khouri IF, Saliba RM, Giralt SA, Lee MS, Okoroji GJ, Hagemeister FB, et al. Nonablative allogeneic hematopoietic transplantation as adoptive immunotherapy for indolent lymphoma: low incidence of toxicity, acute graft-versus-host disease, and treatment-related mortality. Blood. 2001; 98:3595-9.

6. Tomblyn MR, Ewell M, Bredeson C, Kahl BS, Goodman SA, Horowitz MM, et al. Autologous versus reduced-intensity allogeneic hematopoietic cell transplantation for patients with chemosensitive follicular non-Hodgkin lymphoma beyond first complete response or first partial response. Biol Blood Marrow Transplant. 2011; 17:1051-7.

7. Reddy N, Greer JP, Goodman S, Engelhardt B, Oluwole O, Jagasia MH, et al. Long-term outcome after autologous or allogeneic stem cell transplantation in patients with recurrent follicular lymphoma. Bone Marrow Transplant. 2012; 47:1318-20.

8. Ono Y, Mori T, Kato J, Yamane A, Shimizu T, Kikuchi T, et al. Long-term follow-up of reduced-intensity allogeneic hematopoietic stem cell transplantation for refractory or relapsed follicular lymphoma. Am J Hematol. 2012; 87:929-31.

9. Kusumi E, Kami M, Kanda Y, Murashige N, Kishi Y, Suzuki R, et al. Reduced-intensity hematopoietic stem-cell transplantation for malignant lymphoma: a retrospective survey of 112 adult patients in Japan. Bone Marrow Transplant. 2005; 36:205-13.

10. Tada K, Kim SW, Asakura Y, Hiramoto N, Yakushijin K, Kurosawa S, et al. Comparison of outcomes after allogeneic hematopoietic stem cell transplantation in patients with follicular lymphoma, diffuse large B-cell lymphoma associated with follicular lymphoma, or de novo diffuse large B-cell lymphoma. Am J Hematol. 2012; 87:770-5.

11. Cheson BD. Targeted treatment and new agents in follicular lymphoma. Int J Hematol. 2010; 
92:5-11.

12. Grillo-Lopez AJ. Monoclonal antibody therapy for B-cell lymphoma. Int J Hematol. 2002; 76:385-93.

13. Swerdllow S, Campo E, Harris NL. WHO classification of tumours of haematopoietic and lymphoid tissues. Place: Published, France: IARC Press, 2008; 2008

14. Cheson BD, Pfistner B, Juweid ME, Gascoyne RD, Specht L, Horning SJ, et al. Revised response criteria for malignant lymphoma. J Clin Oncol. 2007; 25:579-86.

15. Uchida N, Wake A, Nakano N, Ishiwata K, Takagi S, Tsuji M, et al. Mycophenolate and tacrolimus for graft-versus-host disease prophylaxis for elderly after cord blood transplantation: a matched pair comparison with tacrolimus alone. Transplantation. 2011; 92:366-71.

16. Minagawa K, Yamamori M, Katayama Y, Matsui T. Mycophenolate mofetil: fully utilizing its benefits for GvHD prophylaxis. Int J Hematol. 2012; 96:10-25.

17. Glucksberg H, Storb R, Fefer A, Buckner CD, Neiman PE, Clift RA, et al. Clinical manifestations of graft-versus-host disease in human recipients of marrow from HL-A-matched sibling donors. Transplantation. 1974; 18:295-304.

18. Shulman HM, Sullivan KM, Weiden PL, McDonald GB, Striker GE, Sale GE, et al. Chronic graft-versus-host syndrome in man. A long-term clinicopathologic study of 20 Seattle patients. Am J Med. 1980; 69:204-17.

19. Kernan NA, Bartsch G, Ash RC, Beatty PG, Champlin R, Filipovich A, et al. Analysis of 462 transplantations from unrelated donors facilitated by the National Marrow Donor Program. N Engl J Med. 1993; 328:593-602.

20. Gooley TA, Leisenring W, Crowley J, Storer BE. Estimation of failure probabilities in the presence of competing risks: new representations of old estimators. Stat Med. 1999; 18:695-706.

21. Anderson JR, Cain KC, Gelber RD. Analysis of survival by tumor response. J Clin Oncol. 1983; $1: 710-9$.

22. Cohen Y, Solal-Celigny P, Polliack A. Rituximab therapy for follicular lymphoma: a comprehensive review of its efficacy as primary treatment, treatment for relapsed disease, re-treatment and maintenance. Haematologica. 2003; 88:811-23.

23. Salles G, Ghesquieres H. Current and future management of follicular lymphoma. Int J Hematol. 2012; 96:544-51.

24. Khouri IF, Saliba RM, Erwin WD, Samuels BI, Korbling M, Medeiros LJ, et al. Nonmyeloablative allogeneic transplantation with or without $90 y$ ttrium ibritumomab tiuxetan is potentially curative for relapsed follicular lymphoma: 12-year results. Blood. 2012; 119:6373-8.

25. Hari P, Carreras J, Zhang MJ, Gale RP, Bolwell BJ, Bredeson CN, et al. Allogeneic transplants in 
follicular lymphoma: higher risk of disease progression after reduced-intensity compared to myeloablative conditioning. Biol Blood Marrow Transplant. 2008; 14:236-45.

26. Avivi I, Montoto S, Canals C, Maertens J, Al-Ali H, Mufti GJ, et al. Matched unrelated donor stem cell transplant in 131 patients with follicular lymphoma: an analysis from the Lymphoma Working Party of the European Group for Blood and Marrow Transplantation. Br J Haematol. 2009; 147:719-28.

27. Shea T, Johnson J, Westervelt P, Farag S, McCarty J, Bashey A, et al. Reduced-intensity allogeneic transplantation provides high event-free and overall survival in patients with advanced indolent B cell malignancies: CALGB 109901. Biol Blood Marrow Transplant. 2011; 17:1395-403.

28. Thomson KJ, Morris EC, Milligan D, Parker AN, Hunter AE, Cook G, et al. T-cell-depleted reduced-intensity transplantation followed by donor leukocyte infusions to promote graft-versus-lymphoma activity results in excellent long-term survival in patients with multiply relapsed follicular lymphoma. J Clin Oncol. 2010; 28:3695-700.

29. Pinana JL, Martino R, Gayoso J, Sureda A, de la Serna J, Diez-Martin JL, et al. Reduced intensity conditioning HLA identical sibling donor allogeneic stem cell transplantation for patients with follicular lymphoma: long-term follow-up from two prospective multicenter trials. Haematologica. 2010; 95:1176-82.

30. Rezvani AR, Storer B, Maris M, Sorror ML, Agura E, Maziarz RT, et al. Nonmyeloablative allogeneic hematopoietic cell transplantation in relapsed, refractory, and transformed indolent non-Hodgkin's lymphoma. J Clin Oncol. 2008; 26:211-7.

31. van Besien K, Sobocinski KA, Rowlings PA, Murphy SC, Armitage JO, Bishop MR, et al. Allogeneic bone marrow transplantation for low-grade lymphoma. Blood. 1998; 92:1832-6.

32. Peniket AJ, Ruiz de Elvira MC, Taghipour G, Cordonnier C, Gluckman E, de Witte T, et al. An EBMT registry matched study of allogeneic stem cell transplants for lymphoma: allogeneic transplantation is associated with a lower relapse rate but a higher procedure-related mortality rate than autologous transplantation. Bone Marrow Transplant. 2003; 31:667-78.

33. van Besien K, Loberiza FR, Jr., Bajorunaite R, Armitage JO, Bashey A, Burns LJ, et al. Comparison of autologous and allogeneic hematopoietic stem cell transplantation for follicular lymphoma. Blood. 2003; 102:3521-9.

34. Armand P, Kim HT, Ho VT, Cutler CS, Koreth J, Antin JH, et al. Allogeneic transplantation with reduced-intensity conditioning for Hodgkin and non-Hodgkin lymphoma: importance of histology for outcome. Biol Blood Marrow Transplant. 2008; 14:418-25.

35. Sullivan KM, Weiden PL, Storb R, Witherspoon RP, Fefer A, Fisher L, et al. Influence of acute and chronic graft-versus-host disease on relapse and survival after bone marrow transplantation from 
HLA-identical siblings as treatment of acute and chronic leukemia. Blood. 1989; 73:1720-8.

36. Horowitz MM, Gale RP, Sondel PM, Goldman JM, Kersey J, Kolb HJ, et al. Graft-versus-leukemia reactions after bone marrow transplantation. Blood. 1990; 75:555-62.

37. Kanda J, Hishizawa M, Utsunomiya A, Taniguchi S, Eto $\mathrm{T}$, Moriuchi $\mathrm{Y}$, et al. Impact of graft-versus-host disease on outcomes after allogeneic hematopoietic cell transplantation for adult T-cell leukemia: a retrospective cohort study. Blood. 2012; 119:2141-8.

38. Delgado J, Canals C, Attal M, Thomson K, Campos A, Martino R, et al. The role of in vivo T-cell depletion on reduced-intensity conditioning allogeneic stem cell transplantation from HLA-identical siblings in patients with follicular lymphoma. Leukemia. 2011; 25:551-5.

39. Vigouroux S, Michallet M, Porcher R, Attal M, Ades L, Bernard M, et al. Long-term outcomes after reduced-intensity conditioning allogeneic stem cell transplantation for low-grade lymphoma: a survey by the French Society of Bone Marrow Graft Transplantation and Cellular Therapy (SFGM-TC). Haematologica. 2007; 92:627-34.

40. Khouri IF, Saliba R, Korbling M, Alousi AM, Popat UR, Anderlini P, et al. Bendamustine in combination with fludarabine and rituximab: A novel nonmyeloablative conditioning for allogeneic stem cell transplantation (AST) in patients with lymphoid malignancies. ASCO Meeting Abstracts. 2011; 29:e18511. 